RUTMech, t. XXXIII, z. 88 (4/16), październik-grudzień 2016, s. 323-333

Adam KOTOWSKI ${ }^{1}$

\title{
IMPROVEMENT IN ACCURACY OF NATURAL FREQUENCY DETERMINATION BASED ON THE ENVELOPE OF CROSS-CORRELATION FUNCTION
}

\begin{abstract}
This paper presents a method of improvement of the accuracy in natural frequency determination when having impulse responses from impact testing. A new method is used for obtaining impulse response spectrum. The improvement in natural frequency determination is a result of improving the spectral resolution. For this, the new method uses calculation of surface area under the envelope of the cross-correlation function. This process is repeated by singleharmonic signal generated step-by-step with frequency changed iteratively. Thus the frequency resolution of determined spectrum is independent of length of analysed impulse response.
\end{abstract}

Keywords: natural frequency, determination, improvement, envelope

\section{Introduction}

The use of natural frequency as a diagnostic parameter in structural assessment procedures using vibration monitoring is widely applied. Changes in natural frequencies are called the classical damage indicators. They are the most used damage indicators both formerly and nowadays. The natural frequencies are sensitive to all kinds of damage [1]. In fact, natural frequencies are sensitive indicators of structural integrity. An analysis of periodical frequency measurements can be used to monitor structural condition [2]. The existence of a crack causes reductions in natural frequencies. The value in natural frequency shifts can reach from tens of $\mathrm{Hz}$ to a few $\mathrm{Hz}[3,4]$. Examination of the change in natural frequencies allows an estimation of both the location and size of the crack [5]. Using the fast Fourier transform (FFT) spectral resolution is fixed as an inverse of the duration of the recorded signal $[6,7]$.

\footnotetext{
${ }^{1}$ Autor do korespondencji/corresponding author: Adam Kotowski, Faculty of Mechanical Engineering, Bialystok University of Technology, ul. Wiejska 45C, 15-351 Bialystok, Poland, e-mail: a.kotowski@pb.edu.pl
} 
Then, measurements of natural frequency particularly from short impulse responses are encumbered with errors.

One of the way to improve the frequency resolution is interpolation. It improves the resolution by a few orders $[7,8]$. In order to avoid the limitation in the frequency resolution using FFT, Cawley and Adams investigated this problem and showed that it was possible to obtain frequency resolution of one-tenth of the spacing between the frequency points produced by the Fourier transform [9]. The other way for increasing frequency resolution of the spectrum and improving frequency estimation is zero-padding technique [10, 11].

The cross-correlation function has been used to correlate signal from impact testing to sine wave. In addition, the Hilbert transform has been used to obtain the envelope of the cross-correlation function $[12,13]$. The results of previous investigations have shown that the surface area under the envelope of cross-correlation function has its local highest value in the case of equality of any harmonic between analyzed signal and reference single-harmonic signal. This way, the new procedure results the spectrum with own frequency resolution, e.g. tens of times increased in regard to classical FFT.

\section{Reading natural frequency from 3-dof system impulse response}

An essence of the proposed cross-correlation-envelope method (CCEM) for enhancement the spectral resolution is to correlate recorded impulse response signal $y(k)$ to sine waves generated within a step in frequency $r$. In this way, $r$ value constitutes spectral resolution when calculating a surface area under the envelope of the cross-correlation function. The algorithm is presented in Fig. 1. Symbol $d t$ means a sampling period as the inverse of sampling frequency $f_{s}(d t=1 / f s)$. When algorithm is stopped a plot of the surface area within frequency $f i$ makes a spectrum with resolution $r$. The spectrum involves frequencies from $0 \mathrm{~Hz}$ to $f s / 2 \mathrm{~Hz}$.

The unit impulse response function of a multi degree-of-freedom system can be expressed as follows [14]:

$$
h(t)=\sum_{r=1}^{n} A_{r} \exp \left(-\sigma_{r} t\right) \sin \left(\omega_{d r} t\right)
$$

where: $A_{r}$ - the $r$ th modal constant, $\sigma_{r}$ - the $r$ th modal damping, $\omega_{d r}$ - the $r$ th damped angular frequency of the system. Three degree-of-freedom (3-dof) system impulse response $h(\mathrm{t})$ is considered in this section, $n=3$, see Eq. 1. For instance, it could be an impulse response of a model of mechanical system in the form of the mass-spring system. To obtain the time history of the signal, the values of parameters of impulse response have been randomized. As an 
example, amplitudes reached the values from 0.5 to 1.0, damping from 500 to 600 and frequencies from 3000 to $15000 \mathrm{~Hz}$, where $\omega=2 \pi f$.

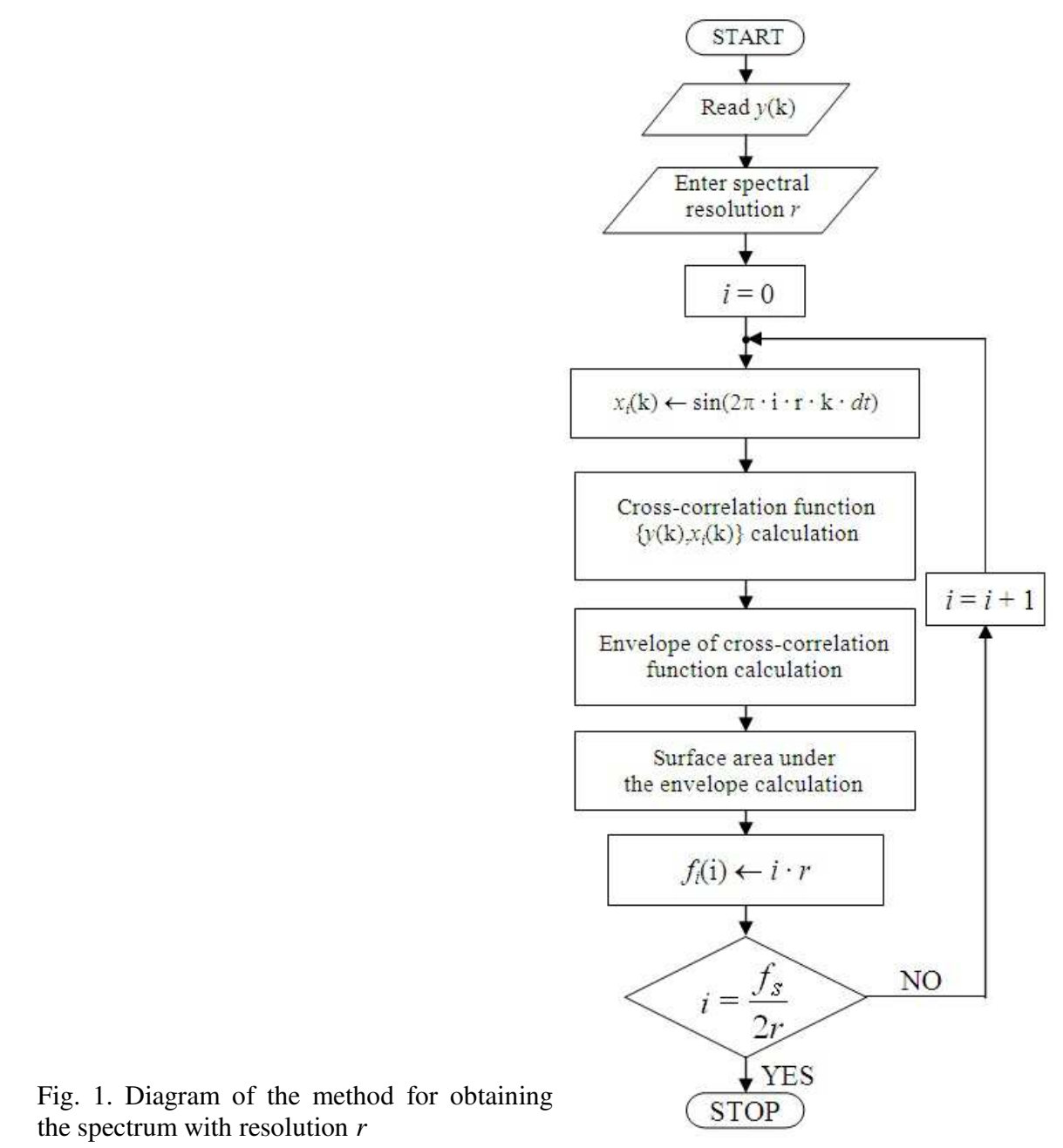

The analyzed signal has been synthesized numerically by sampling frequency equal to $65536 \mathrm{~Hz}$ and 1024 samples in length. Hence, frequency resolution by using FFT is $64 \mathrm{~Hz}$. The exemplary impulse response signal under consideration is shown in Fig. 2. The proposed method of obtained spectrum can be utilized by the same resolution that FFT produces $(64 \mathrm{~Hz})$ but it also makes a possibility to have the spectral resolution much higher without increasing the signal length. Spectra obtained using FFT and CCEM are shown in Fig. 3. A set of calculations and measurements for three cases of random signal parameters values is shown in Table 1 and 2. Here, the results also in- 
clude two types of spectrum obtaining, i.e. FFT and CCEM by $8 \mathrm{~Hz}$ and $1 \mathrm{~Hz}$ spectral resolution.

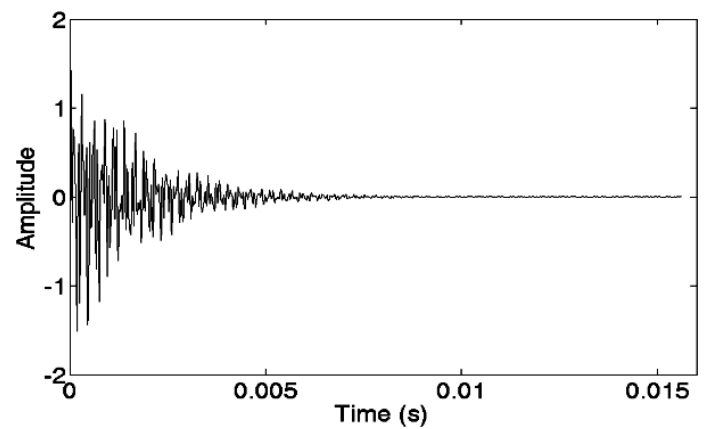

Fig. 2. Exemplary 3-dof system impulse response

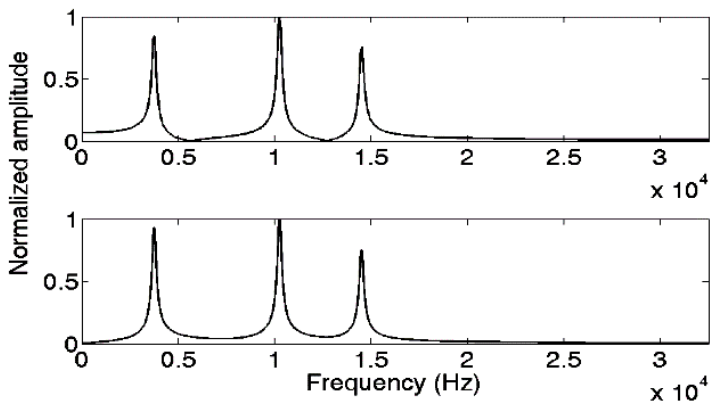

Fig. 3. Impulse response spectra obtained using FFT (top) and CCEM (bottom)

Table 1. Real frequencies

\begin{tabular}{|c|c|c|c|}
\hline Case & $f_{1}[\mathrm{~Hz}]$ & $f_{2}[\mathrm{~Hz}]$ & $f_{3}[\mathrm{~Hz}]$ \\
\hline 1 & 3957.17 & 10485.38 & 14800.28 \\
\hline 2 & 3035.71 & 10849.13 & 14933.99 \\
\hline 3 & 3706.05 & 10031.83 & 14276.92 \\
\hline
\end{tabular}

Table 2. Measured frequencies using FFT and CCEM

\begin{tabular}{|c|c|c|c|c|}
\hline Case & Method & $f_{1}[\mathrm{~Hz}]$ & $f_{2}[\mathrm{~Hz}]$ & $f_{3}[\mathrm{~Hz}]$ \\
\hline \multirow{3}{*}{1} & $\mathrm{FFT}$ & 3968 & 10496 & 14784 \\
\cline { 2 - 5 } & $\mathrm{CCEM}, \Delta \mathrm{f}=8 \mathrm{~Hz}$ & 3960 & 10488 & 14800 \\
\cline { 2 - 5 } & $\mathrm{CCEM}, \Delta \mathrm{f}=1 \mathrm{~Hz}$ & 3958 & 10486 & 14800 \\
\hline \multirow{3}{*}{2} & $\mathrm{FFT}$ & 3008 & 10816 & 14912 \\
\cline { 2 - 5 } & $\mathrm{CCEM}, \Delta \mathrm{f}=8 \mathrm{~Hz}$ & 3040 & 10848 & 14936 \\
\cline { 2 - 5 } & $\mathrm{CCEM}, \Delta \mathrm{f}=1 \mathrm{~Hz}$ & 3037 & 10849 & 14934 \\
\hline \multirow{3}{*}{3} & $\mathrm{FFT}$ & 3712 & 10048 & 14272 \\
\cline { 2 - 5 } & $\mathrm{CCEM}, \Delta \mathrm{f}=8 \mathrm{~Hz}$ & 3704 & 10032 & 14280 \\
\cline { 2 - 5 } & $\mathrm{CCEM}, \Delta \mathrm{f}=1 \mathrm{~Hz}$ & 3707 & 10032 & 14277 \\
\hline
\end{tabular}






Fig. 4. Absolute differences between real and measured frequencies for 1st, 2nd and 3rd case

The best accuracy of frequency determination has been obtained for CCEM by frequency resolution equal to $1 \mathrm{~Hz}$, see Fig. 4 - black bar. Absolute differences between real and measured frequencies obtained using FFT reached a range from $5 \mathrm{~Hz}$ to over $30 \mathrm{~Hz}$. However, absolute differences between real and measured frequencies obtained using CCEM with $1 \mathrm{~Hz}$ resolution reached from nearly $0 \mathrm{~Hz}$ to about $1.3 \mathrm{~Hz}$. Thus, the accuracy of frequency determination using CCEM is several or even dozens of times higher than using FFT.

\section{Reading natural frequency from 3-dof system impulse response in the presence of noise}

Impulse response of 3-dof system has been noised with $20 \mathrm{~dB}$ and $40 \mathrm{~dB}$ signal-to-noise ratios (SNR) given as follows:

$$
S N R_{d B}=20 \lg \frac{A_{s}}{A_{n}}
$$

where $A_{s}$ and $A_{n}$ mean root mean square (RMS) of an analyzed signal and RMS of a noise, respectively [15]. To obtain the time history of impulse response, the values of parameters in Eq. 2 have been randomized at the same ranges as presented in section 3 . The noised impulse responses has been calculated with the same sampling frequency and samples in length as in section 3. The noised impulse responses of 3-dof system are shown in Fig. 5. Spectra of considered impulse responses are shown in Figs. 6-7. Differences between real and measured frequencies obtained using FFT have reached the same values $20 \mathrm{~dB}$ and $40 \mathrm{~dB}$ of SNR (Table 3). In this cases, differences are in the range 
from $22 \mathrm{~Hz}$ to $33 \mathrm{~Hz}$, see Fig.8. By using CCEM, differences between real and measured frequencies have reached the range of $10.3-13.2 \mathrm{~Hz}$ for $20 \mathrm{~dB}$ of SNR and the range of $0.1-3.3 \mathrm{~Hz}$ for $40 \mathrm{~dB}$ of SNR. Once again, the accuracy of frequency determination using CCEM is several or even tens of times higher than using FFT.


Fig. 5. Noised 3-dof system impulse response with 20dB (left) and 40dB (right) of SNR

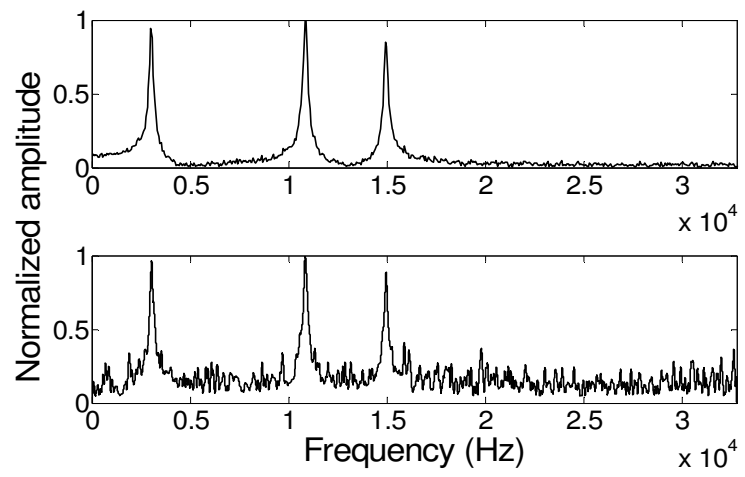

Fig. 6. Spectra of noised impulse response with $20 \mathrm{~dB}$ of SNR obtained using FFT (top) and CCEM (bottom)



Fig. 7. Spectra of noised impulse response with 40dB of SNR obtained using FFT (top) and CCEM (bottom) 
Table 3. Real and measured frequencies in the case of $20 \mathrm{~dB}$ and $40 \mathrm{~dB}$ of SNR

\begin{tabular}{|c|c|c|}
\hline$f_{1}[\mathrm{~Hz}]$ & $f_{2}[\mathrm{~Hz}]$ & $f_{3}[\mathrm{~Hz}]$ \\
\hline \multicolumn{3}{|c|}{ Real } \\
\hline 3035.71 & 10849.12 & 14933.99 \\
\hline \multicolumn{3}{|c|}{ Measured using FFT, SNR=20dB } \\
\hline 3008 & 10816 & 14912 \\
\hline Measured using CCEM, SNR=20dB \\
\hline 3046 & 10836 & 14945 \\
\hline \multicolumn{3}{|c|}{ Measured using FFT, SNR=40dB } \\
\hline 3008 & 10816 & 14912 \\
\hline \multicolumn{3}{|c|}{ Measured using CCEM, SNR=40dB } \\
\hline 3039 & 10849 & 14936 \\
\hline
\end{tabular}

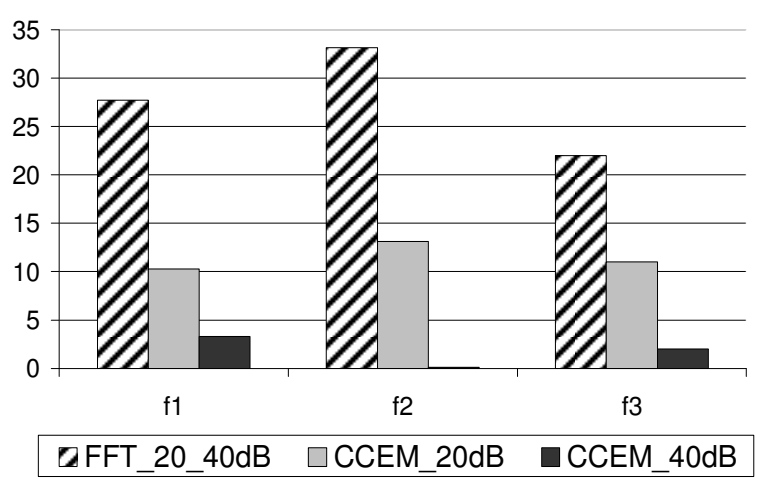

Fig. 8. Absolute differences in $\mathrm{Hz}$ between real and measured frequencies by $20 \mathrm{~dB}$ and $40 \mathrm{~dB}$ of SNR

\section{Results for the case of integer and non-integer frequency resolution multiplication}

In this section, spectral analysis of impulse response of single-degree-offreedom (SDOF) system for different damped frequency being the multiplication of frequency resolution is presented. For this case damped frequency of SDOF system is considered in the following form

$$
f_{d}=k \Delta f+z \Delta f
$$

where $\Delta f$ is the frequency resolution, $k$ is a factor for integer multiplication of the frequency resolution $(k=1,2,3, \ldots)$ and $z$ is a factor within the range 0 to 1. To obtain the impulse responses, factor $k$ has been changed from 91 to 100 . By setting $z$ factor, frequency $f_{d}$ can obtain the values as the non-integer multiplication of the frequency resolution. In this way, frequency $f_{d}$ will be within the range of $5824 \mathrm{~Hz}$ to $6464 \mathrm{~Hz}$. The analyzed impulse responses have been 
synthesized numerically by sampling frequency equal to $65536 \mathrm{~Hz}$ and 1024 samples in length. Hence, the frequency resolution by using FFT is unchangeable and equal to $\Delta f_{F F T}=65536 / 1024=64 \mathrm{~Hz}$, while the frequency resolution by using CCEM can be fixed in an arbitrary way, regardless of the recorded signal length, e.g. $\Delta f_{C C E M}=1 \mathrm{~Hz}$. Exemplary impulse response of SDOF system is shown in Fig. 9.



Fig. 9. SDOF system impulse response

The results from No. 1 to 10 (Table 4) have shown that in the case of integer multiplication of the frequency resolution there is no difference between real and measured frequency using both methods (FFT, CCEM). A completely different status is by non-integer multiplication of the frequency resolution. Difference between real and measured frequency depends on $z$ factor significantly when using FFT (Fig. 10).



Fig. 10. Absolute differences between real and measured frequencies as a function of $z$ factor 
Table 4. Real and measured frequencies using FFT and CCEM for integer and non-integer multiplication of the frequency resolution

\begin{tabular}{|c|c|c|c|c|c|}
\hline & & & & \multicolumn{2}{c|}{} \\
No. & $k$ & $z$ & $\begin{array}{c}\text { Real frequency } \\
{[\mathrm{Hz}]}\end{array}$ & \multicolumn{2}{|c|}{$[\mathrm{Hz}]$} \\
\cline { 5 - 7 } & & & & FFT & CCEM \\
\hline 1 & 91 & 0.0 & 5824 & 5824 & 5824 \\
\hline 2 & 92 & 0.0 & 5888 & 5888 & 5888 \\
\hline 3 & 93 & 0.0 & 5952 & 5952 & 5952 \\
\hline 4 & 94 & 0.0 & 6016 & 6016 & 6016 \\
\hline 5 & 95 & 0.0 & 6080 & 6080 & 6080 \\
\hline 6 & 96 & 0.0 & 6144 & 6144 & 6144 \\
\hline 7 & 97 & 0.0 & 6208 & 6208 & 6208 \\
\hline 8 & 98 & 0.0 & 6272 & 6272 & 6272 \\
\hline 9 & 99 & 0.0 & 6336 & 6336 & 6336 \\
\hline 10 & 100 & 0.0 & 6400 & 6400 & 6400 \\
\hline 11 & 100 & 0.1 & 6406.4 & 6400 & 6407 \\
\hline 12 & 100 & 0.2 & 6412.8 & 6400 & 6413 \\
\hline 13 & 100 & 0.3 & 6419.2 & 6400 & 6420 \\
\hline 14 & 100 & 0.4 & 6425.6 & 6400 & 6426 \\
\hline 15 & 100 & 0.5 & 6432.0 & 6400 & 6432 \\
\hline 16 & 100 & 0.6 & 6438.4 & 6464 & 6439 \\
\hline 17 & 100 & 0.7 & 6444.8 & 6464 & 6445 \\
\hline 18 & 100 & 0.8 & 6451.2 & 6464 & 6451 \\
\hline 19 & 100 & 0.9 & 6457.6 & 6464 & 6458 \\
\hline 20 & 100 & 1.0 & 6464.0 & 6464 & 6464 \\
\hline & & & & & \\
\hline
\end{tabular}

Maximum difference then is a half of the frequency resolution $\triangle f_{F F T}=$ $=32 \mathrm{~Hz}$. In the case of the use of CCEM, differences between real and measured frequencies are far lower in comparison to FFT measurements. Then, maximum difference is $0.8 \mathrm{~Hz}$ (Fig. 10 black bar).

\section{Conclusions}

The use of cross-correlation function and its envelope allows to obtain signal spectrum. The proposed non-Fourier method for accurate measurement of natural frequency is comprised of the process of calculation of cross-correlation function between the impulse response signal and sine wave. Then, a surface area under the envelope of the cross-correlation function is calculated. The frequency resolution in this method is regardless of the signal length and can be adjusted. Thus, the frequency resolution can be increased significantly and the accuracy of determination of natural frequencies can be improved. The examples have shown that the proposed method gives much 
higher accuracy in frequency determination beside FFT, also in the presence of noise. The results in the case of integer and non-integer frequency resolution multiplication have indicated advantages of the presented method.

\section{Acknowledgement}

This work was supported by Bialystok University of Technology under work No. S/WM/1/2016.

\section{References}

[1] Palacz M., Krawczuk M.: Vibration parameters for damage detection in structures, J. Sound Vibration, 249 (2002) 999-1010.

[2] Salawu O.S.: Detection of structural damage through changes in frequency: a review, Eng. Structures, 19 (1997) 718-723.

[3] Patil D.P., Maiti S.K.: Detection of multiple cracks using frequency measurements, Eng. Fracture Mech., 70 (2003) 1553-1572.

[4] Dilena M., Dell'Oste M.F., Morassi A.: Detecting cracks in pipes filled with fluid from changes in natural frequencies, Mech. Systems Signal Processing, 25 (2011) 3186-3197.

[5] Choubey A., Sehgal D.K., Tandon N.: Finite element analysis of vessels to study changes in natural frequencies due to cracks, Int. J. Pressure Vessels Piping, 83 (2006) 181-187.

[6] Bendat J.S., Piersol A.G.: Engineering applications of correlation and spectral analysis, Wiley Interscience, New York 1980.

[7] Gasior M.: Improving Frequency Resolution of Discrete Spectra, PhD thesis, AGH University of Science and Technology, Kraków 2006.

[8] Gasior M.: Improving Frequency Resolution of Discrete Spectra - Algorithms of Three-Node Interpolation, LAP LAMBERT Academic Publishing, 2010.

[9] Cawley P., Adams R.D.: Improved frequency resolution from transient tests with short record lengths. Journal of Sound and Vibration, Vol. 64, No. 1, 1979, pp. 123-132.

[10] Quinn B.G. Recent advances in rapid frequency estimation. Digital Signal Processing, Vol. 19, No. 6, 2009, pp. 942-948.

[11] Dunne J.F. A fast time-domain integration method for computing non-stationary response histories of linear oscillators with discrete-time random forcing. J. Sound Vibration, 254 (2002) 635-676.

[12] Thrane N.: The Hilbert Transform, Technical Review 3, Brüel\&Kjær, Naerum, Denmark 1984.

[13] Thrane N., Wismer J., Konstantin-Hansen H., Gade S.: Practical use of the "Hilbert transform", Application Note, Brüel\&Kjær, Naerum, Denmark 1999.

[14] Ahn S.J., Jeong W.B., Yoo W.S.: Improvement of impulse response spectrum and its application, J. Sound Vibration, 288 (2005) 1223-1239. 
[15] Katunin A.: Localization of damage in beam-like structures applying timefrequency distributions to modal shapes of vibration, Diagnostyka, 17 (2016) 53-58.

\section{POPRAWA DOKŁADNOŚCI WYZNACZANIA CZECTOTLIWOŚCI DRGAŃ WLASNYCH W OPARCIU O OBWIEDNIĘ FUNKCJI KORELACJI WZAJEMNEJ}

\section{Streszczenie}

Praca przedstawia sposób poprawy dokładności wyznaczania częstotliwości drgań własnych mając odpowiedzi z badań impulsowych. Nowej metody używa się w celu znalezienia widma odpowiedzi impulsowej. Poprawa wyznaczania częstotliwości drgań własnych jest wynikiem poprawy rozdzielczości widmowej. W tym celu nowa metoda wyznacza pole powierzchni pod obwiednią funkcji korelacji wzajemnej. Proces ten dokonuje się cyklicznie włącznie z generacją fali harmonicznej krok po kroku wraz z iteracyjną zmianą jej częstotliwości. W ten sposób, rozdzielczość częstotliwościowa wyznaczanego widma jest niezależna od długości analizowanej odpowiedzi impulsowej.

Słowa kluczowe: częstotliwość drgań własnych, wyznaczanie, poprawa, obwiednia

DOI: $10.7862 / \mathrm{rm} .2016 .26$

Otrzymano/received: 14.11.2016 r.

Zaakceptowano/accepted: $12.12 .2016 \mathrm{r}$. 